\title{
Blood loss during and after transurethral resection of prostate: A prospective study
}

\author{
Shrestha BM, Prasopshanti K, Matanhelia SS, Peeling WB \\ Consultant Surgeons, Department of Urology, Royal Gwent Hospital, Newport, Gwent, UK.
}

\begin{abstract}
Objectives: Transurethral resection of prostate (TURP) is the gold standard treatment for symptomatic prostatic bladder outlet obstruction. Haemorrhage during and after TURP can lead to significant morbidity and mortality. The purpose of this study was to assess the influence of anaesthesia, operating time, weight of resected prostatic tissue and its histology on blood loss during and after TURP and to revisit the available body of evidence in the literature of urology.

Materials and methods: This is a prospective study of a cohort of 100 consecutive patients who had undergone TURP over a period of one year, where the data was collected on a performa specifically designed for the study, which included the type of anaesthesia administered, resection time, amount of blood lost during and after TURP, weight of the resected prostatic tissue and histology.

Results: Sixty seven patients underwent TURP under spinal anaesthesia (SA) and 33 under general anaesthesia (GA). The median intraoperative (SA: 89.95 (5-936); GA: 105.40 (5-517) mls), postoperative (SA: 72.37 (15-387); GA: 136.43 (11-969) mls) and total (SA: 162.32 (29-1200); GA: 241.83 (21-1251) mls) blood losses were not significantly different between the two groups (95\% C.I. -9.90 to $19.22, \mathrm{p}=0.46)$. The total operating time (SA: 29.70 (10-55); GA: 29.80 (10-65) minutes) and weight of resected prostate (SA: 21.90 (3-45); GA: 18.00 (4-60) gms) were similar between the two groups. There was a trend towards increased blood loss when BPH was associated with prostatitis $(\mathrm{N}=8)$. Of these, 3 patients required blood transfusion as compared to 1 patient in rest of the group, although this was not statistically significant (95\% C.I - 67.2 to $1120.4, \mathrm{p}=0.87)$.

Conclusions: The intraoperative, postoperative and total blood losses related to TURP were not influenced by the type of anaesthesia, resection time, weight of the resected prostate and the histology.
\end{abstract}

Key Words: Transurethral resection of prostate, blood loss, anaesthesia, prostatitis, carcinoma, aspirin

$\mathrm{T}$ ransurethral resection of the prostate (TURP) remains the gold standard surgical treatment of benign prostatic hyperplasia (BPH) causing symptomatic bladder outlet obstruction (BOO) $)^{1}$. Haemorrhage during and after TURP can lead to significant morbidity and occasionally prove fatal. Some authors have reported reduced blood loss when TURP is carried out under $\mathrm{SA}^{2,3}$, while others have failed to demonstrate this relationship ${ }^{4,5,6}$. The other possible variables which can influence the blood loss are the weight of prostate resected, resection time, histology of the gland, presence of urinary tract infection (UTI) and preoperative administration of aspirin ${ }^{5,7}$. In this article, we present the outcomes of the afore-mentioned variables on the blood loss during and after TURP from a prospective study and review the literature relevant to contemporary practice.

\section{Maaterials and methods}

A cohort of 100 consecutive patients with symptomatic $\mathrm{BOO}$, who had undergone TURP during a period of one year, were included in the study and data was collected prospectively in a specifically designed performa. Preoperative work-up included clinical evaluation, full blood count, estimation of urea and electrolytes, coagulation profile, midstream urine culture, estimation of flow rate, electrocardiogram, x-rays of chest and abdomen, ultrasound scan of kidneys and bladder, and a transrectal ultrasound scan of prostate. UTI, when present, was treated with appropriate antibiotics. Sixty seven patients underwent TURP under SA using $0.5 \%$ bupivacaine and 33 patients received general anaesthetic. The type of anaesthesia was decided by the anaesthetists, although patients with respiratory and cardiovascular co-morbidities were more likely to be given SA.

\footnotetext{
Correspondence

BM Shrestha,

Consultant Transplant Surgeon,

Sheffield Kidney Institute,

Sheffield S5 7AU; UK.

E-mail: shresthabm@doctors.net.uk.
} 
All patients underwent TURP using a $24 \mathrm{Fr}$ gauge fibre-lit resectoscope with continuous irrigation of the bladder with $1.5 \%$ glycine solution. The resection time was measured from the insertion to the removal of the resectoscope. For each patient, the weight of the resected prostatic tissue, type of anaesthesia, histology of the prostate and the blood loss during and after TURP was recorded. Normal saline was used for irrigating the bladder postoperatively. All irrigating fluid used during the operation and postoperatively up to the time of removal of the catheter was collected, heparinised (1500 IU of heparin for every 8 litres of fluid), mixed well and after recording the total volume, samples were collected and the haemoglobin content was estimated using a HemoCue haemoglobinometer (Fig 1). The blood loss was calculated using the following equation:

$\mathrm{Hb}$ content of the irrigants $(\mathrm{gm} / \mathrm{L}) \times$ Volume (L) x 1000

Blood loss in mls = - $\mathrm{Blood} \mathrm{Hb}(\mathrm{gm} / \mathrm{L}) \times 5.2$

The results were assessed using Mann-Whitney U test, with $\mathrm{p}<0.005$ taken to indicate statistical significance.

\section{Results}

The demography of the patients is shown in Table 1. There was no significant difference between the age of the patients, resection time, weight of the tissue resected, and intraoperative, postoperative and total blood losses between the patients operated under SA and GA. Although the median postoperative blood loss in GA group appeared to be almost double of those operated under SA, this did not reach statistical significance $(95 \%$ C.I. -9.90 to $19.22, p=0.46)$. The blood loss per gram of resected tissue (Table 2) did not show any correlation with the histology of the gland, although there was a trend towards increased blood loss in the presence of prostatitis compared to benign prostatic hyperplasia alone (95\% C.I - 67.2 to 1120.4 , $\mathrm{p}=0.87)$. Three patients with prostatitis required blood transfusion in the postoperative period. Twelve patients had associated UTI diagnosed in the post-operative period where the total blood loss was not significantly different from than those without infection (Table 3). Pre-operative catheterisation of bladder to relieve acute urinary retention did not influence the blood loss in 25 patients (Table 4). Aspirin was discontinued 10 days before TURP in 8 patients and interestingly, the total blood loss was less than the rest of the patients (Table 5). No significant changes in the serum electrolyte concentration, TURP syndrome or mortality were observed post-operatively.

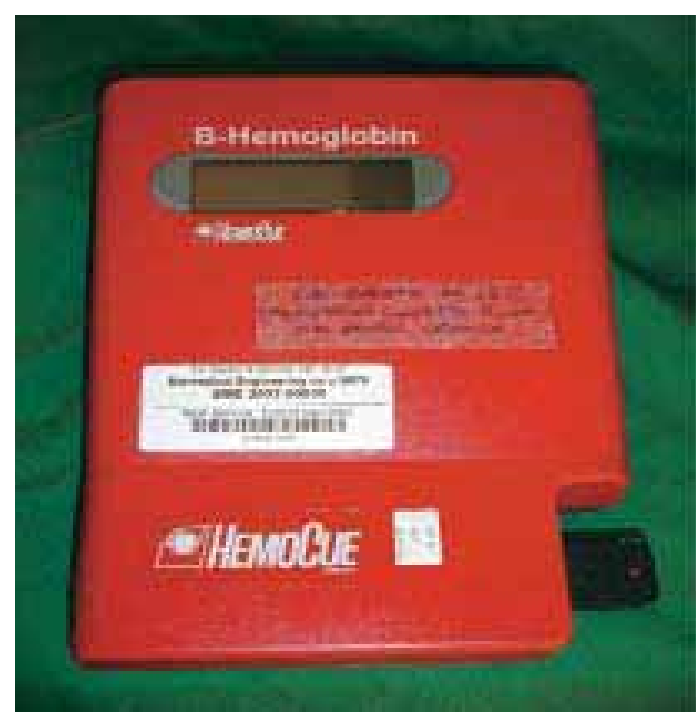

Fig 1: Showing HaemoCue meter used to estimate haemoglobin content 
Table 1: Patient demography and blood losses

\begin{tabular}{|l|c|c|c|}
\hline Data, : median (range) & SA $(\mathbf{N}=\mathbf{6 7})$ & GA (N=33) & Whole group \\
\hline Age & $72(60-89)$ & $70(60-85)$ & $71.3(60-89)$ \\
\hline Duration of operation (minutes) & $29.70(10-55)$ & $29.80(10-65)$ & $29.73(10-65)$ \\
\hline Weight of resected tissue(g) & $21.90(3-45)$ & $18.00(4-60)$ & $20.6(3-60)$ \\
\hline Blood loss (ml) & & & $95(5-936)$ \\
Intraoperative & $89.95(5-936)$ & $105.40(5-517)$ & $93.5(11-969)$ \\
Postoperative & $72.37(15-387)$ & $136.43(11-969)$ & $188.5(21-1251)$ \\
Total & $162.32(29-1200)$ & $241.83(21-1251)$ & 9.39 \\
\hline Mean blood loss per gram (mls/g) & 7.41 & 13.43 & \\
\hline
\end{tabular}

Table 2: Total blood loss per gram of resected prostatic tissue and histology

\begin{tabular}{|l|c|c|c|}
\hline & SA & GA & Whole group \\
\hline Benign prostatic hyperplasia $(\mathrm{ml})$ & $7(\mathrm{~N}=56)$ & $10.80(\mathrm{~N}=24)$ & $8(\mathrm{~N}=80)$ \\
\hline Adenocarcinoma $(\mathrm{ml})$ & $9.60(\mathrm{~N}=7)$ & $17.1(\mathrm{~N}=5)$ & $12.8(\mathrm{~N}=12)$ \\
\hline BPH with prostatitis $(\mathrm{ml})$ & $16.10(\mathrm{~N}=4)$ & $24.10(\mathrm{~N}=4)$ & $20.1(\mathrm{~N}=8)$ \\
\hline
\end{tabular}

Table 3: TURP in presence of UTI $(\mathrm{N}=12)$

\begin{tabular}{|l|c|}
\hline Mean duration of operation $(\mathrm{min})$ & 26 \\
\hline Mean weight of resected tissue $(\mathrm{g})$ & 13.2 \\
\hline Mean blood loss per gram $(\mathrm{ml} / \mathrm{g})$ & 20.3 \\
\hline Total blood loss per prostatectomy $(\mathrm{ml})$ & 263 \\
\hline
\end{tabular}

Table 4: TURP with preoperative urethral catheters $(\mathrm{N}=25)$

\begin{tabular}{|l|c|}
\hline Resection time $(\mathrm{min})$ & 26.6 \\
\hline Weight resected $(\mathrm{g})$ & 15.3 \\
\hline Total blood loss per prostatectomy $(\mathrm{ml})$ & 240 \\
\hline
\end{tabular}

Table 5: TURP in patients on preoperative aspirin $(\mathrm{N}=8)$

\begin{tabular}{|l|c|}
\hline Number of patients & $8(\mathrm{SA}=7 ; \mathrm{GA}=1)$ \\
\hline Mean age & $71.3(65-77)$ \\
\hline Mean resection time $(\mathrm{min})$ & 23.8 \\
\hline Mean resected weight $(\mathrm{g})$ & 19.4 \\
\hline Mean blood loss $(\mathrm{ml})$ & 96.5 \\
\hline Mean blood loss per gram $(\mathrm{ml})$ & 4.97 \\
\hline
\end{tabular}

\section{Discussion}

Despite the development of new technologies, TURP is still considered as the gold standard for surgical treatment for patients with moderate or severe lower urinary tract symptoms related to BPH. Several studies have been carried out in the past to evaluate and modify the factors influencing the morbidities related to the procedure, particularly the blood loss. Administration of SA is shown to be associated with less blood loss in some studies, which has not been confirmed by others ${ }^{2}$, $4,5,6$. The weight of the resected prostate and a resection time longer than 60 minutes was shown to correlate with increased blood loss in two studies ${ }^{5,8}$, while this has been refuted by other study ${ }^{6}$. Likewise, the histology of the prostate is shown to bear no relationship to the perioperative blood $\operatorname{loss}^{8}$. In our own study, the weight of the resected prostatic tissue, resection time and total blood loss following TURP were similar to other published studies, however there was no convincing correlation between the afore-mentioned variables and the perioperative blood loss.

Concomitant UTI is associated with significant secondary haemorrhage following TURP although there is no associated increased perioperative blood 
loss. Administration of prophylactic antibiotics has not shown to influence the outcome 9 . Intake of aspirin while undergoing TURP is associated with increased blood loss which has been confirmed in prospective randomised placebo-controlled trials and its discontinuation 10 days prior to surgery is recommended ${ }^{10,11}$. Patients with high risk of deep vein thrombosis and pulmonary embolism should receive low molecular weight heparin in the perioperative period as there is no increased risk of bleeding ${ }^{12}$.

The type of irrigation fluid such as $1.5 \%$ glycine and $2.7 \%$ sorbitol- $0.5 \%$ mannitol as an irrigating solution for TURP has not shown significant differences in the outcome $^{13}$. Similarly, use of warm irrigation fluid had no influence on the blood loss, however this reduced shivering and was comforting to the patients ${ }^{14}$.

In an attempt to reduce perioperative blood loss, transurethral vaporesection (TURVP) was compared with TURP in prospective randomized trials comparing clinical outcome and morbidity, which showed no significant differences in any of the parameters evaluated $^{15,16}$. However, other investigators have shown beneficial effect of the use of a thick vapour resection loop for TURP coupled with higher generator settings for prostates $>40$ grams, as this significantly reduced operating time, blood loss, irrigants requirement, nursing contact time, and duration of catheterization, besides providing clear vision during surgery and ease of resection without concomitant in complications ${ }^{17}$. The major disadvantage is the lack of a histological specimen with this version of prostate vaporization, which can lead to missed diagnosis of clinically significant cancers ${ }^{18}$.

A combination of interstitial laser coagulation (ILC) control using an Nd:YAG laser followed by resection of the bladder neck or the median lobe with limited TURP led to reduction of blood loss and of the risk of TUR syndrome $^{19}$. This has been confirmed in ex vivo models of porcine kidneys showing better haemostasis than TURP $^{20}$. More lately, bipolar resection using the Vista device exhibited significantly less blood loss compared to TURP and is shown to be effective and safe especially in patients with larger prostate and high risk factors ${ }^{21}$.

Recent randomised trial comparing Thulium laser resection of the prostate-tangerine technique (TmLRPTT) and standard TURP has shown TmLRP-TT as an almost bloodless procedure with high efficacy and little perioperative morbidity ${ }^{22}$.

Other minimally invasive treatments for $\mathrm{BPH}$ are transurethral needle ablation (TUNA) and transurethral microwave thermotherapy (TUMT). TUNA is performed by placing interstitial radiofrequency (RF) needles through the urethra and into the lateral lobes of the prostate, causing heat-induced coagulation necrosis. The tissue is heated to $110^{\circ} \mathrm{C}$ at an $\mathrm{RF}$ power of $456 \mathrm{KHz}$ for approximately 3 minutes per lesion ${ }^{23}$. Likewise, TUMT involves the insertion of a specially designed Foley-type catheter into the bladder, allowing a microwave antenna to be positioned within the prostatic fossa. Microwaves are then created to heat and destroy the hyperplastic prostate tissue ${ }^{24}$. The coagulation defect thus created, widens the urethral passage. The data comparing the outcomes of minimally invasive treatments with the TURP are inconclusive regarding blood loss, length of catheterization and hospital stay. Long-term comparative trials are needed to determine if the minimally invasive therapies are superior to standard TURP 25 .

Pathologically BPH is characterized by an increased proliferation of stromal and acinar cells, sustained by increased vascularization (neoangiogenesis) and increased expression of vascular endothelial growth factor $^{26}$. Recent studies have also shown that finasteride reduces dihydrotestosterone synthesis, interacts with endothelial growth factors, thus reducing angiogenesis and the prostatic volume. This represents a fundamental advance in limiting intra- and postoperative bleeding in patients undergoing TURP. This hypothesis has been tested by several investigators in prospective randomised trials and have concluded that preoperative administration of finasteride is associated with significant reduction of perioperative blood loss which is evidenced by maintenance of normal postoperative haemoglobin and minimal requirement of blood transfusion ${ }^{27,28,29}$.

With therelativelyrecentintroductionofpharmacological and other surgical treatment modalities, the performance of TURP appears to be in decline. A recent survey from a UK centre has shown $31 \%$ reduction in the rate of TURP in the year 2000 compared to 1990 and the major indication for TURP is urinary retention ${ }^{30}$.

In conclusion, from the data accrued from our own study, there was no correlation between the blood loss and the type of anaesthetic administered, resection time, and weight of the resected prostate, their histology, preoperative catheterisation and UTI. It was apparent that there was no set pattern of blood loss related to afore-mentioned variables and it was impossible to predict which patient was most likely to have increased perioperative blood loss following TURP. A meticulously performed TURP with reasonable speed and attention to details is the way forward in reducing perioperative blood loss. 


\section{References}

1. Lynch M,Anson K. Time to rebrand transurethral resection of the prostate? Curr Opin Urol. 2006; 16(1):20-4.

2. Abrams PH, Shah PJ, Bryning K, et al. Blood loss during transurethral resection of the prostate. Anaesthesia 1982; 37(1):71-3.

3. Madsen PO, Wagenknecht LV, Knuth OE. Blood loss in transurethral resection of the prostate. Urologe. 1970; 9(3):122-6.

4. McGowan SW, Smith GF. Anaesthesia for transurethral prostatectomy. A comparison of spinal intradural analgesia with two methods of general anaesthesia. Anaesthesia. 1980; 35(9):847-53.

5. Levin K, Nyren O, Pompeius R. Blood loss, tissue weight and operating time in transurethral prostatectomy. Scand J Urol Nephrol. 1981; 15(3):197-200.

6. Nielsen KK, Andersen K, Asbjorn J, et al. Blood loss in transurethral prostatectomy: epidural versus general anaesthesia. Int Urol Nephrol. 1987; 19(3):287-92.

7. Smyth R, Cheng D, Asokumar B, Chung F. Coagulopathies in patients after transurethral resection of the prostate: spinal versus general anesthesia. Anesth Analg. 1995; 81(4):680-5.

8. Kirollos MM, Campbell N. Factors influencing blood loss in transurethral resection of the prostate (TURP): auditing TURP. Br J Urol. 1997; 80(1):111-5.

9. Harvey $\mathrm{MH}$, Leese T, Lloyd D, Osborn DE. Antibiotic prophylaxis and secondary haemorrhage following transurethral resection of the prostate: a prospective trial. Br J Urol. 1986; 58(4):450-2.

10. Nielsen JD, Holm-Nielsen A, Jespersen J, et al. The effect of low-dose acetylsalicylic acid on bleeding after transurethral prostatectomy-a prospective, randomized, double-blind, placebo-controlled study. Scand J Urol Nephrol 2000; 34(3):194-8.

11. Ala-Opas MY, Gronlund SS. Blood loss in longterm aspirin users undergoing transurethral prostatectomy. Scand J Urol Nephrol. 1996; 30(3):203-6.

12. Bejjani BB, Chen DC, Nolan NG, Edson M. Minidose heparin in transurethral prostatectomy. Urology. 1983; 22(3):251-4.

13. Inman $\mathrm{RD}$, Hussain $\mathrm{Z}$, Elves $\mathrm{AW}$, et al. $\mathrm{A}$ comparison of $1.5 \%$ glycine and $2.7 \%$ sorbitol$0.5 \%$ mannitol irrigants during transurethral prostate resection. J Urol. 2001; 166(6):221620.
14. Heathcote PS, Dyer PM. The effect of warm irrigation on blood loss during transurethral prostatectomy under spinal anaesthesia. $\mathrm{Br} \mathrm{J}$ Urol. 1986; 58(6):669-71.

15. Helke C, Manseck A, Hakenberg OW, Wirth MP. Is transurethral vaporesection of the prostate better than standard transurethral resection? Eur Urol. 2001; 39(5):551-7.

16. Holmes M, Cox J, Stewart J, et al. Thick vs thin loop transurethral resection of the prostate: a double-blind prospective trial of early morbidity. BJU Int. 2002; 89(3):197-201.

17. Gupta NP, Doddamani D, Aron M, Hemal AK. Vapor resection: a good alternative to standard loop resection in the management of prostates $>40$ cc. J Endourol. 2002; 16(10):767-71.

18. Hon NH, Brathwaite D, Hussain Z, et al. A prospective, randomized trial comparing conventional transurethral prostate resection with PlasmaKinetic vaporization of the prostate: physiological changes, early complications and long-term followup. J Urol. 2006; 176(1):205-9.

19. Corvin S, Schneede P, Siakavara E, et al. Interstitial laser coagulation combined with minimal transurethral resection of the prostate for the treatment of benign prostatic hyperplasia. J Endourol. 2002; 16(6):387-90.

20. Reich O, Schneede P, Corvin S, et al. Combination of interstitial laser coagulation and transurethral resection of the prostate: ex vivo evaluations. Urology. 2003; 61(6):1172-6.

21. Li XD, Cheng S, Rui XF, et al. Transurethral prostatectomyusing Vistabipolarradiofrequency system: comparison with conventional transurethral resection of the prostate. Arch Androl. 2006; 52(4):293-8.

22. Xia SJ, Zhuo J, Sun XW, et al. Thulium Laser versus Standard Transurethral Resection of the Prostate: A Randomized Prospective Trial. Eur Urol. 2008; 53(2):382-90.

23. Bouza C, Lopez T, Magro A, et al. Systematic review and meta-analysis of Transurethral Needle Ablation in symptomatic Benign Prostatic Hyperplasia. BMC Urol. 2006; 6:14.

24. Herrmann TR, Gross AJ, Schultheiss D, et al. Transurethral microwave thermotherapy for the treatment of BPH: still a challenger? World J Urol. 2006; 24(4):389-96.

25. Ohigashi T, Nakamura K, Nakashima J, et al. Long-term results of three different minimally invasive therapies for lower urinary tract symptoms due to benign prostatic hyperplasia: comparison at a single institute. Int $\mathrm{J}$ Urol. 2007; 14(4):326-30. 
26. Haggstrom S, Torring N, Moller $\mathrm{K}$, et al. Effects of finasteride on vascular endothelial growth factor. Scand J Urol Nephrol. 2002; 36(3):182-7.

27. Crea G, Sanfilippo G, Anastasi G, et al. Presurgical finasteride therapy in patients treated endoscopically for benign prostatic hyperplasia. Urol Int. 2005; 74(1):51-3.

28. Donohue JF, Sharma H, Abraham R, et al. Transurethral prostate resection and bleeding: a randomized, placebo controlled trial of role of finasteride for decreasing operative blood loss. J Urol. 2002; 168(5):2024-6.
29. Sandfeldt L, Bailey DM, Hahn RG. Blood loss during transurethral resection of the prostate after 3 months of treatment with finasteride. Urology. 2001; 58(6):972-6.

30. Wilson JR, Urwin GH, Stower MJ. The changing practice of transurethral prostatectomy: a comparison of cases performed in 1990 and 2000. Ann R Coll Surg Engl. 2004; 86(6):42831. 